\title{
Word processing in Parkinson's Disease is impaired for action verbs but
}

\section{not for concrete nouns}

Véronique Boulenger ${ }^{1}$, Laura Mechtouff ${ }^{2}$, Stéphane Thobois ${ }^{2}$, Emmanuel Broussolle $^{2}$, Marc Jeannerod $^{1}$ and Tatjana A. Nazir ${ }^{1}$

${ }^{1}$ L2C2-Institut des Sciences Cognitives, UMR 5230 CNRS/Université Claude Bernard Lyon I, Bron, France

${ }^{2}$ Service de Neurologie, Hôpital Neurologique Pierre Wertheimer, Université Claude Bernard Lyon I, INSERM U864, Lyon, France.

Running Title: Action word processing in Parkinson's Disease

\section{Corresponding Authors:}

Drs Véronique Boulenger and Tatjana A. Nazir

L2C2-Institut des Sciences Cognitives

67 boulevard Pinel

69675 Bron Cedex, France

Tel: $(+33)$ 04.37.91.12.55

Fax: (+33) 04.37.91.12.10

boulenger@isc.cnrs.fr, nazir@isc.cnrs.fr 


\section{Abstract}

Recent studies have demonstrated that processing of action words recruits cortical motor regions that are also involved in the planning and execution of the actions words refer to. The functional role of these regions in word understanding remains, however, to be clarified. The present study investigates this issue by examining the impact of Parkinson's Disease (PD) on lexical decision performance for action words, relative to concrete nouns, in a masked priming paradigm. Priming effects for the two word categories were measured in nondemented PD patients off and on dopaminergic treatment, and in healthy participants. Our results revealed that although overall performances did not differ between verbs and nouns, priming effects showed a clear dissociation between word categories. While priming for concrete nouns was not affected by Levodopa intake, it dissociated as a function of treatment for action verbs. No priming was actually obtained for action verbs in PD patients off dopaminergic treatment. Following Levodopa intake, this deficit recovered, however, because priming effects for verbs became comparable to those for concrete nouns and similar to performance of healthy participants. Overall, this study thus brings compelling evidence that processing lexico-semantic information about action words depends on the integrity of the motor system.

Key-words: Selective vulnerability - Action words - Parkinson's Disease - Masked priming effects 


\section{Introduction}

Recent investigations of the cortical network that underlies language abilities have revealed that the same brain areas that are involved in the planning and execution of body movements are also recruited when words describing these movements are perceived (AzizZadeh et al., 2006; Boulenger et al., 2006; Buccino et al., 2005; Hauk et al., 2004; Oliveri et al., 2004; Pulvermüller et al., 2005ab; Tettamanti et al., 2005). Using fMRI, Hauk et al. (2004), for instance, have shown that premotor and motor cortex are active during passive reading of words that refer to actions performed with different body parts. More intriguingly, this language-related cortical activity followed the somatotopy of cortical motor regions and thus varied spatially depending on whether the words denoted actions performed with the face, arms, or legs (see also Tettamanti et al., 2005 for related findings using sentences). A similar pattern of results was also reported by Aziz-Zadeh et al. (2006), who showed overlapping motor activation between passive reading of action-related sentences and action observation. Using TMS, Buccino et al. (2005) further substantiated these findings by revealing modulations of left motor cortex excitability (i.e. reduced amplitude of motor-evoked potentials) during listening to hand- and leg-action-related sentences when TMS was concurrently applied to the corresponding motor areas.

However, while the results of these studies clearly demonstrate that motor regions are recruited during processing of action-related language, they do not allow clarifying the crucial question about the functional role of these areas in language: are cortical motor regions critical to word understanding? Part of this flaw comes from the fact that most previous studies cannot clearly determine when, subsequent to word onset, language-related motor activity actually emerges. As a matter of fact, activity in motor regions could simply arise 
consecutively to word identification, and once the word is understood, it could trigger motor imagery of the action it describes. Mental motor imagery is indeed known to involve motor areas (Jeannerod, 1994; Jeannerod \& Frak, 1999).

Two recent studies (Boulenger et al., 2006; Pulvermüller et al., 2005a) nevertheless provided robust evidence that language-related motor activity occurs early following word onset. Using MEG, Pulvermüller et al. (2005a) could show that, at 130-150 ms after stimulus onset, spoken face- and leg-related action words elicited activity in perisylvian language areas. This activity was almost immediately followed by a short-lived somatotopic activity along the motor strip (170-200 ms post-stimulus). Given that lexico-semantic effects generally occur within $200 \mathrm{~ms}$ following word presentation (Hauk et al., 2006; Preissl et al., 1995; Pulvermüller et al., 1999; Sauseng et al., 2004; Sereno \& Rayner, 2003), the authors suggested that motor regions may play an active role in action word comprehension. In a similar vein, Boulenger et al. (2006), who performed continuous and online analyses of finegrained movement kinematics while participants were engaged in a lexical decision task, demonstrated that within the same early time window after word onset $(<200 \mathrm{~ms})$, processing of action verbs interfered with the concurrent execution of a reaching movement (i.e. reduced amplitude and longer latency of the wrist acceleration peak for verb- relative to noun-stimuli). These interference effects were interpreted as reflecting competition for common resources between processes involved in movement execution and processes involved in action word encoding.

A more definitive test of the role of motor regions in language comprehension, however, would come from neuropsychological studies that show selective deficits in action word processing following cortical motor lesions - or in relation to movement disorders in general 
(see Mahon \& Caramazza, 2005). Selective deficits for verbs have indeed been described in patients with progressive supranuclear palsy (Daniele et al., 1994) or with motor neuron disease (Bak et al., 2001; Bak \& Hodges, 2004). In addition, Bak et al. (2006) recently reported the case of a familial occurrence of selective deficit of verb processing in association with movement disorder. The present study aimed at corroborating these findings by assessing the impact of Parkinson's Disease (PD) on action word processing.

PD is a neurodegenerative disease caused by a dopaminergic deficiency of the nigrostriatal pathway, primarily characterized by motor disorders (i.e. akinesia/bradykinesia, rigidity and tremor), although deficits in cognitive functions and subtle semantic language deficits have also been reported (for a review, see Pillon et al., 2001). Neuroimaging studies have revealed that during movement execution, regions involved in motor preparation, which receive strong projection from the striato-frontal loop (Alexander et al., 1986; DeLong, 1990), are underactivated in PD patients (Jahanshahi et al., 1995; Jenkins et al., 1992; Playford et al., 1992; Rascol et al., 1992, 1994). This impairment improves, however, following dopaminergic treatment (Haslinger et al., 2001), which increases dopamine levels in the striatum and restores the function of the basal ganglia. Electrophysiological studies have also shown that the amplitude of pre-movement activity is reduced in PD patients (Dick et al., 1987; Jahanshahi et al., 1995; Oishi et al., 1995; Shibasaki et al., 1978). Here again, the deficit recovers after Levodopa ingestion (Dick et al., 1987). If premotor and motor regions that are involved in movement preparation and execution play also a role in action word understanding, PD patients deprived of dopaminergic treatment should show selective deficits in processing these words but not in processing other classes of words, such as concrete nouns. Furthermore, Levodopa intake, which re-establishes normal activation level in premotor and 
motor areas via the striato-frontal loop, should not only restore motor deficits but also the selective deficit for action verbs.

To test this, the present study compares lexical decision latencies (i.e. the time it takes to decide whether a letter string is a word or not) for action verbs and concrete nouns of nondemented PD patients (off and on dopaminergic treatment) using a masked priming paradigm. In such a paradigm, a prime-word is presented in close spatial and temporal proximity with other visual stimuli, so that it is not consciously perceived (i.e. it is masked). A target-word, which is identical to the prime but written in different case (TABLE-table), is subsequently displayed and participants have to indicate as quickly as possible whether the target is a word. Masked prime-words, though not consciously perceived, pre-activate essential parts of the cerebral networks for word processing (Dehaene et al., 2001) and thereby lead to considerable reduction in response times to immediately following target words (Ferrand et al., 1994; Forster \& Davis, 1984). Given that visual features of prime and target differ, cross-case priming effects are based on activation of lexical-semantic representation of words. Moreover, in as much as masked primes are not consciously perceived, priming effects in this paradigm cannot be attributed to conscious strategic processes that may take place after lexical access (for the prime) had occurred.

Since regions involved in motor preparation are under-activated in PD patients (Jahanshahi et al., 1995; Jenkins et al., 1992; Playford et al., 1992; Rascol et al., 1992, 1994), lexical access for masked verbs should be less efficient in PD if these regions really contribute to action word processing. Priming effects for action verbs, but not for concrete nouns, should therefore be reduced or even suppressed in PD patients off treatment. On treatment, however, 
no difference in priming effects between the two word classes should be observed, and PD patients should perform similarly to healthy controls.

\section{Methods}

\section{Participants}

Ten PD patients ( 6 males and 4 females; mean age 62.8 years old \pm 8.7 ) and ten healthy control participants ( 6 males and 4 females; mean age 62.4 years old \pm 6.2 ), matched for age, gender, education and socio-economic status, participated in the study. All were French native speakers, had normal or corrected-to-normal vision, and were right-handed according to the Edinburgh Inventory (mean score: 0.92 at the Edinburgh Inventory, Oldfield, 1971; Table 1). None of the patients had a history of neurological or psychiatric disease other than PD. Control participants had no history of current or past neurological and psychiatric disease. All participants signed an informed consent prior to the experiment and were fully informed about the experimental procedure.

Patients fulfilled the UK Parkinson's Disease Brain Bank criteria for idiopathic PD (Gibb \& Lees, 1988). They showed good responsiveness to Levodopa therapy and were hospitalized for medical check-up. They had been diagnosed between 1 to 17 years prior to their participation in this study. They performed the experiment twice in the same day: once off antiparkinsonian medication for at least 12 hours (OFF-phase), and once 60 minutes after intake of a supraliminar dose of levodopa $100 \mathrm{mg}$ (usual morning levodopa-equivalent dose +25\%; ON-phase; see Thobois, 2006 for Dopa equivalence). Motor disability was evaluated using the motor part III of the Unified Parkinson's Disease Rating Scale (UPDRS Part III, Fahn \& Elton, 1987) in OFF- and ON-states. Cognitive performance was assessed using the 
Mattis Dementia Rating Scale (DRS; Schmidt et al., 1994) and the Beck Depression Inventory (BDI; Beck et al., 1961, 1979). Though slightly diminished, patient's DRS scores were in the normal range given their age. BDI scores also indicate that depression threshold was not reached. Scores obtained for the different tests are reported in Table 1.

$<$ TABLE 1 ABOUT HERE >

\section{Materials}

Target stimuli: One hundred and forty words (70 action verbs and 70 concrete nouns) were selected from the French lexical database "Lexique" (New et al., 2001). Verbs, all in the infinitive form, denoted actions performed with the hand or the arm (e.g. draw), and nouns, in singular form, referred to imageable, concrete entities that cannot be manipulated (e.g. mill). Words that could be used as both nouns and verbs were excluded from the selection. Stimuli were matched for relevant lexical variables including word frequency, length in letters, number of syllables, bigram and trigram frequency (Table 2). Word age of acquisition was also controlled using empirical ratings performed by 15 volunteers on a seven-point scale $(1=$ [0-2 years] and $7=$ [older than 13 years]; Gilhooly \& Logie, 1980). Word imageability was estimated following the same procedure by another 15 volunteers (with $0=$ impossible and 6 = very easy to generate a mental image of the word).

One hundred and forty pseudo-words, constructed by changing one letter from real nouns or real verbs, were added as fillers to perform the lexical decision task. Pseudo-words were thus either "pseudo-nouns" (70 items) or "pseudo-verbs" (70 items) and were all pronounceable. They were matched to words for relevant lexical variables (Table 2). Verbs and pseudo-verbs were also carefully matched for endings, such that as many verbs as 
pseudo-verbs (61/70 and 59/70 respectively) ended with "er", which is a frequent ending for verbs in French.

\section{$<$ TABLE 2 ABOUT HERE >}

Prime stimuli: Primes consisted either of the same 140 words and 140 pseudo-words that served as targets, or of a group of 280 non-words (i.e. consonant strings not pronounceable in French; e.g., szmfr). The total of 560 stimuli was divided in two equivalent experimental lists. In one list, half of the target words and pseudo-words was preceded (primed) by an identical prime (i.e. identical-prime condition), while the other half was primed with a consonants string (i.e. consonants-prime condition). In the second list, target-prime relation was reversed. Half of participants were tested with the first list and the other half with the second list. To ensure that priming effects were not simply due to visual summation of prime and target stimuli, prime stimuli were displayed in upper case while target stimuli were presented in lower case.

\section{Procedure}

Stimuli were displayed at the center of the screen of a PC monitor, using E-Prime software. As schematically indicated in Figure 1, a display sequence started with a central fixation cross (500 ms), followed by a string of eight hash-marks $(100 \mathrm{~ms})$, the prime $(50 \mathrm{~ms})$, another string of hash-marks (100 ms) and the target stimulus. The target remained on the screen until participants indicated by a button press on one of two pre-selected keys on the computer keyboard, whether the stimulus was a word or not. Stimulus Onset Asynchrony (SOA; i.e. time interval between the onset of the prime and the onset of the target) was $150 \mathrm{~ms}$. Participants were instructed to respond as quickly and as accurately as possible. For half of 
participants, response to words was given with the right hand and response to pseudo-words with the left hand. For the other half of participants, this relation was reversed. Stimulus presentation was randomized and a training phase consisting of 5 words and 5 pseudo-words (different from the experimental stimuli) preceded the experiment. Subsequent to the experiment, participants were asked whether they had identified any primes.

$<$ FIGURE 1 ABOUT HERE >

\section{Statistical Analyses}

Mean reaction times (in milliseconds) were measured. Trials for which participants made an erroneous response and trials with reaction times below or above 2.5 standard deviations from individual means (a total of $2.64 \%$ trials for controls and $4.35 \%$ and $3.69 \%$ for patients in OFF and ON respectively) were excluded from the analysis. Response latencies for nouns, verbs, pseudo-nouns and pseudo-verbs were first calculated individually and were then averaged over all participants. Analyses of variance (ANOVAs) with repeated measures allowed examining the effects of four main factors: "Lexicality" (words vs. pseudo-words), "Word Category" (only for words; action verbs vs. concrete nouns), "Prime" (only for words; identical-prime vs. consonants-prime) and "Phase" (only for PD patients; OFF vs. ON). Significant interactions were assessed using one-tailed and two-tailed paired t-tests.

\section{Results}

None of the participants reported to have identified the primes.

In the following, results are first presented for control participants, and then for PD patients in the OFF- and ON-phases, respectively. 


\section{Control participants}

The percentage of excluded "error" trials was $1 \% \pm 1.91$ for nouns, $1.28 \% \pm 1.72$ for verbs and $3.21 \% \pm 3.09$ for pseudo-words.

Table 3a summarizes individual performance of the 10 control participants ( $\mathrm{C} 1$ to $\mathrm{C} 10)$ in the two priming conditions for nouns and verbs stimuli. Net priming effects, which are the difference in response time for the consonants-prime condition and the identical-prime condition, are also given. Note that negative scores specify that reaction times were faster in the consonants-prime condition. Average performance with standard deviations is plotted at the bottom of the table. Except for participants C9 and C10, all participants were slower in the consonants- than in the identical-prime condition. This indicates that the priming procedure was effective for the majority of participants.

\section{$<$ TABLE 3a ABOUT HERE >}

The ANOVA showed the typical effect of "Lexicality" that is observed in this type of task, that is, mean reaction times were significantly longer to pseudo-words $(1081 \mathrm{~ms} \pm 283)$ than to words $(791 \mathrm{~ms} \pm 136 ;[\mathrm{F}(1,9)=25.79 ; \mathrm{p}=.0007])$. The main factor "Word Category" had a marginally significant effect on performance $([\mathrm{F}(1,9)=4.08 ; \mathrm{p}=.0742 ; \mathrm{ns}])$, indicating slightly faster reaction times to verbs than to nouns. Such variations can occur when lexical factors are not entirely balanced between the two word classes. This is not problematic, however, because we evaluate net priming effects, which compare performance for the same word class with itself (in the consonants- and identical-prime conditions). Mean reaction times to concrete nouns were $806 \mathrm{~ms} \pm 132$ and to action verbs $776 \mathrm{~ms} \pm 144$. The factor 
"Prime" had a significant effect on performance $([\mathrm{F}(1,9)=15.29 ; \mathrm{p}=.0036])$, with shorter mean reaction times in the identical-prime condition $(768 \mathrm{~ms} \pm 150)$ than in the consonantsprime condition ( $813 \mathrm{~ms} \pm 126$ ). Finally, no interaction between "Word Category" and "Prime" was obtained $([\mathrm{F}(1,9)=1.49 ; \mathrm{p}=\mathrm{ns}])$, demonstrating that net priming effects were equivalent for action verbs $(40 \mathrm{~ms} \pm 32)$ and concrete nouns (51 ms \pm 46$)$. Reaction times in the identical-prime condition were $756 \mathrm{~ms} \pm 155$ for verbs and $780 \pm 144$ for nouns. In the consonants-prime condition, they were $796 \mathrm{~ms} \pm 133$ and $832 \mathrm{~ms} \pm 124$, respectively.

\section{PD patients}

- OFF-phase

The percentage of excluded "error" trials was $6.57 \% \pm 6.69$ for nouns, $2.71 \% \pm 4.19$ for verbs and $6.57 \% \pm 4.58$ for pseudo-words. Overall mean reaction times for PD patients in the OFF-phase (975 ms \pm 157$)$ were generally slower than for the control group (791 ms \pm 137 ; F $(1,18)=7.962 ; \mathrm{p}<.011)$

Table $3 \mathrm{~b}$ plots the data of the ten PD patients in the OFF-phase. For concrete nouns, all but one participant (PD7) showed clear effects of priming. This indicates that the priming procedure was effective for PD patients as well. For action verbs, by contrast, no priming was observed for PD2, PD8 and PD10. Moreover, for the remaining 6 participants who showed priming in both conditions, smaller priming effects were observed for verbs than for nouns.

$<$ TABLE 3b ABOUT HERE >

The ANOVA revealed a significant effect of "Lexicality", i.e. mean reaction times were longer for pseudo-words $(1254 \mathrm{~ms} \pm 327)$ than for words $(975 \mathrm{~ms} \pm 163$; [F $(1,9)=11.06 ; \mathrm{p}$ 
$=.0089])$. The effect of "Lexicality" testifies that PD patients performed the task adequately. No effect of "Word Category" was obtained ([F $(1,9)=.042 ; \mathrm{p}=\mathrm{ns}])$, indicating that patients responded to action verbs as rapidly as to concrete nouns (968 ms \pm 161 vs. $982 \mathrm{~ms} \pm 156$ respectively). The factor "Prime" had a significant effect on performance $([\mathrm{F}(1,9)=41.32 ; \mathrm{p}$ $<.0001])$, with shorter mean reaction times in the identical-prime condition $(953 \mathrm{~ms} \pm 163)$ than in the consonants-prime condition (997 ms \pm 152 ). However, in contrast to healthy participants, PD patients in OFF showed a significant interaction between "Word Category" and "Prime" $([\mathrm{F}(1,9)=6.71 ; \mathrm{p}=.0291])$, demonstrating that net priming effects differed for concrete nouns and action verbs. Mean reaction times were actually shortened by $81 \mathrm{~ms}( \pm 61)$ when a target noun was primed by an identical-prime (942 ms \pm 163 ) rather than by a consonants-prime $(1023 \mathrm{~ms} \pm 155 ; \mathrm{t}(9)=4.22 ; \mathrm{p}=.001$, one-tailed; $\mathrm{p}=.002$, two-tailed $)$. For action verbs, no significant priming effect $(6 \mathrm{~ms} \pm 37)$ emerged (966 ms \pm 171 for identicalprimes vs. $972 \mathrm{~ms} \pm 153$ for consonants-primes; $\mathrm{t}(9)=.533 ; \mathrm{p}=.303$ one-tailed; $\mathrm{p}=.607$ twotailed).

A direct comparison of net priming effects between control participants and PD patients in the OFF-phase showed no difference for nouns $(\mathrm{t}(18)=1.249 ; \mathrm{p}=.228$, two-tailed), but a clear significant difference for verbs $(\mathrm{t}(18)=-2.403 ; \mathrm{p}=.027$, two-tailed). Hence, while masked priming for concrete nouns had the same effect on response time for healthy controls and for PD patients, masked priming for action verbs was clearly less effective for PD patients than for controls.

- ON-phase

Only eight of the ten PD patients could perform the experiment during the ON-phase. Two could not perform the task because of severe dyskinesias. 
The percentage of excluded "errors" trials was $4.1 \% \pm 4.89$ for nouns, $2.14 \% \pm 2.25$ for verbs and $7.95 \% \pm 7.17$ for pseudo-words. Overall mean reaction times for the eight PD patients during the ON-phase $(883 \mathrm{~ms} \pm 125)$ did not differ significantly from those of healthy controls $(791 \mathrm{~ms} \pm 137 ; \mathrm{F}(1,16)=2.195 ; \mathrm{p}=\mathrm{ns})$.

Table 3c plots individual data for each of the eight PD patients in the ON-phase. For concrete nouns and action verbs alike, all but two participants (PD2, PD5; and PD2, PD4, respectively) showed clear and comparable effects of priming.

\section{$<$ TABLE 3C ABOUT HERE >}

Like in the OFF-phase, mean reaction times were significantly longer for pseudo-words (1190 $\mathrm{ms} \pm 257)$ relative to words $(883 \mathrm{~ms} \pm 122 ;[\mathrm{F}(1,7)=18.34 ; \mathrm{p}=.0036])$. No effect of "Word Category" was obtained $([\mathrm{F}(1,7)=.410 ; \mathrm{p}=\mathrm{ns}])$, indicating that patients responded to action verbs in a comparable way than to concrete nouns ( $890 \mathrm{~ms} \pm 130$ vs. $875 \mathrm{~ms} \pm 162$, respectively). A significant effect of "Prime" was also observed $([\mathrm{F}(1,7)=8.36 ; \mathrm{p}=.0233])$, showing that patients recognized words faster when they were preceded by an identical-prime (860 $\mathrm{ms} \pm 117)$ than by a consonants-prime $(905 \mathrm{~ms} \pm 132)$. However, contrary to the OFFphase and similarly to performances of healthy participants, in the ON-phase, no interaction between "Word Category" and "Prime" emerged $([\mathrm{F}(1,7)=.010 ; \mathrm{p}=\mathrm{ns}])$. In other words, priming effects in the ON-phase were equivalent for action verbs (44 $\mathrm{ms} \pm 47 ; 868 \mathrm{~ms} \pm 124$ for identical-primes vs. $912 \mathrm{~ms} \pm 140$ for consonants-primes) and concrete nouns (46 ms \pm 59 ; $852 \mathrm{~ms} \pm 118$ vs. $898 \mathrm{~ms} \pm 132$ respectively). 
Note also that UPDRS scores dropped considerably between the OFF- and ON-phases (Table 1). The difference between the two phases was highly significant $([\mathrm{F}(1,7)=21.217 ; \mathrm{p}$ $<.0002]$ ), which indicates that motor performance improved. However, simple regression analyses between UPDRS scores and response time or priming effects in lexical decision, did not show a systematic relation between the two measures. UPDRS scores and response time thus appear to capture different aspects of the deficit.

- Comparison of performance in the OFF- and ON-phases (with 8 PD patients)

To directly compare performance in the two phases, we discarded the data from the two patients that could not be tested in the ON-phase.

A comparison of mean reaction times for words in the OFF- and ON-phases did not reveal any significant effect of "Phase" ([F $(1,7)=1.648 ; p=n s])$. No main effect of "Word Category" was observed $([\mathrm{F}(1,7)=.2327 ; \mathrm{p}=\mathrm{ns}])$, but a main effect of "Prime" emerged ([F $(1,7)=27.571 ; \mathrm{p}=.0012])$. The interaction between these three factors was also significant $([\mathrm{F}(1,7)=7.382 ; \mathrm{p}=.0299])$, revealing the differential net priming effects for verbs, relative to nouns, in the OFF- and ON-phases. Paired t-tests revealed that net priming effects for verbs were as expected smaller in the OFF- $(13 \mathrm{~ms} \pm 26)$ than in the ON-phase $(44 \mathrm{~ms} \pm 47 ; \mathrm{t}(7)=-$ 2.057; $\mathrm{p}=.039$, one-tailed; $\mathrm{p}=.079$, two-tailed). A comparison of individual data in Tables $3 \mathrm{~b}$ and $3 \mathrm{c}$ shows that for all but one of the 8 PD patients (PD4), net priming increased between the two phases. By contrast, net priming effects for nouns did not differ systematically between the OFF- $(72 \mathrm{~ms} \pm 54)$ and ON-phases $(46 \mathrm{~ms} \pm 59 ; \mathrm{t}(7)=1.051 ; \mathrm{p}$ $=.164$, one-tailed $; \mathrm{p}=.328$, two-tailed). 
Figure 2 plots mean performance of the eight PD patients during the ON- and OFF-phases together with performance of healthy controls. Data are plotted for noun- and verb-stimuli as a function of priming conditions. As evident from this comparison, despite the fact that overall reaction times varied, significant priming effects were observed in all but one condition: action verbs in the OFF-phase of PD patients.

$<$ FIGURE 2 ABOUT HERE >

\section{Discussion}

The present study aimed at determining to what extent motor regions contribute to action word processing by comparing masked priming effects for action verbs and concrete nouns in non-demented PD patients off and on dopaminergic treatment. Our results reveal that processing of action words can be selectively disrupted following a pathology that affects the motor system. When PD patients were deprived of dopaminergic treatment, that is, when motor disability was strongest, masked priming effects for action words were nearly absent. At the same time however, robust priming effects were observed for concrete nouns, thus discarding the possibility that lack of priming for verbs was due to an overall decrease in the ability of PD patients to capture information from masked words. Interestingly, following Levodopa intake, priming effects for action verbs restored and appeared as strong as for concrete nouns, and comparable to those of healthy controls. Hence, just as for motor preparation and execution (Dick et al., 1987; Haslinger et al., 2001), processing of action words in PD varies with treatment, which suggests that cortical motor regions are indeed involved in lexical access. Coherent with previous studies that showed deficits for verb 
processing in patients with progressive supranuclear palsy (Daniele et al., 1994) or motor neuron disease (Bak et al., 2001, 2006; Bak \& Hodges, 2004), our results thus provide strong evidence that aspects of the meaning of action words are represented in cortical motor areas. However, since the dissociation between nouns and verbs in our study was only evident when priming effects were considered (but not when overall reaction times or error rates were measured), deficit in action word processing following motor impairments must be subtle. Other parts of the cortical language network might therefore be sufficient to correctly identify these words. Note nevertheless that lack of priming for action verbs in our PD patients was obtained during the practically defined OFF-period, that is, while weaning was partial, temporary and minimal. The real impact of the motor system for processing action words might therefore have been underestimated.

Previous studies have shown that non-demented PD patients can display deficits on more general measures of language functioning such as sentence comprehension (Grossman, 1999; Grossman et al., 1991, 1992, 2001; Lieberman et al., 1990, 1992; Natsopoulos et al., 1991), language production (Beatty \& Monson, 1989) or lexical ambiguity resolution (Copland et al., 2000). Verb learning (Grossman et al., 1994) and selective (oral) verb production deficits have also been reported (Bertella et al., 2002; Peran et al., 2003). While these language troubles have classically been attributed to difficulties in processing grammatical information, especially about verbs, recent studies have suggested that they may rather reflect limitations of cognitive resources in terms of working memory or general slow down of information processing (Grossman, 1999; Grossman et al., 2002, 2005). Both interpretations, however, do not seem to account for the lack of priming effect for action verbs that we observed in our PD patients. First, masked priming is known to reflect automatic activation of lexico-semantic information at the word level (Ferrand et al., 1994; Forster \& Davis, 1984; Greenwald et al., 
1996). The deficit in action word processing of our PD patients may therefore occur at this particular level rather than at the grammatical level. Second, the fact that PD patients displayed normal priming effects for concrete nouns during the phase where no priming was observed for action verbs, is incompatible with the hypothesis that postulates a general slowing down of lexical retrieval for words in PD patients (Grossman et al., 2002). Similarly, accounts that relate deviant language processing in PD to a generalized alteration in neural signal-to-noise ratio (Angwin et al., 2003; Bloxham et al., 1987; Kischka et al., 1996; Spitzer \& Neumann, 1996) - which could thus result in less efficient processing of weak signals such as masked words - cannot explain the dissociation we found between action verbs and concrete nouns. In the same way, changes in the time-course of semantic activation observed in some PD patients as well as in healthy subjects who ingested Levodopa (Angwin et al., 2003, 2004ab; Arnott et al., 2001) may not explain why priming effects in our study were absent in PD patients off treatment only for action verbs. Finally, for practical reasons, all PD patients performed the experiment first off and then on dopaminergic treatment. This could suggest that performance for action verbs improved in the ON-period because of learning. But here again, such learning bias cannot account for the dissociation between the two word categories, since performance for concrete nouns was comparable in the two phases.

According to our hypothesis, masked priming effects for action verbs are absent in PD patients because cortical motor regions, which do not function adequately during dopamine depletion (Dick et al., 1987; Jahanshahi et al., 1995; Jenkins et al., 1992; Oishi et al., 1995; Playford et al., 1992; Rascol et al., 1992, 1994; Shibasaki et al., 1978), are involved in lexical access. This hypothesis joins recent theoretical arguments which consider language understanding either as a form of mental simulation involving the "mirror neuron system" (Gallese \& Lakoff, 2005; Rizzolatti \& Fadiga, 2004; Tettamanti et al., 2005), or as the result 
of Hebbian correlation learning between perisylvian language areas and motor regions (Pulvermüller, 2005). The mirror neuron system consists of visuomotor neurons, located in premotor and motor cortices, which respond to action execution, action observation and action-related sounds (Aziz-Zadeh et al., 2002, 2004; Buccino et al., 2001; Fadiga et al., 1995; Gallese et al., 1996; Kohler et al., 2002; Rizzolatti et al., 1996ab). It has been suggested to code action content at an abstract level, accessible by language (Gallese \& Lakoff, 2005). Hence, the meaning of action words could be assessed through the mirror neuron system by mentally simulating the described actions. The "Hebbian learning model", by contrast, postulates that meaning-related information about action words may be represented in frontocentral motor areas (Pulvermüller, 1996, 2001, 2005), because functional links between cortical systems for language and action would develop during language acquisition (Pulvermüller et al., 2005a; Shtyrov et al., 2004). Any variable that affects the normal functioning of cortical motor regions should thus affect the understanding of action-related language.

Whatever the exact underlying mechanism, the selective deficit for action verbs that we observed in the present study confirms previous suggestions that cortical representations of concrete nouns and action verbs involve partly distinct cortical regions (Boulenger et al., 2007; Caramazza \& Hillis, 1991; Damasio \& Tranel, 1993; Hillis et al., 2003), with the latter extending into cortical motor areas (Aziz-Zadeh et al., 2006; Boulenger et al., 2006; Hauk et al., 2004; Oliveri et al., 2004; Pulvermüller et al., 2005a; Shtyrov et al., 2004). The verb processing deficit in PD is mild though, which suggests that the contribution of cortical motor regions to action word understanding may be relatively small. It is important to note here that human cortical motor regions seem to be involved in processing words describing human actions only, and are not recruited during processing of words describing actions performed 
by other species (Buccino et al., 2004; Mason et al., 2004; see also Boulenger et al., 2007 for related findings). One possible contribution of cortical motor regions to action word understanding could therefore be that of providing pragmatic knowledge about the actions described by the words.

In line with this speculation, neuropsychological studies have shown that focal brain disease or lesions can independently disrupt semantic and functional aspects of knowledge. Hence, patients with semantic dementia, for instance, can display degraded conceptual knowledge about objects (e.g., they fail to produce correct semantic descriptions about objects), while pertaining knowledge about how to use the objects appropriately (Buxbaum et al., 1997; Hodges et al., 1998; Lauro-Grotto et al., 1997). Conversely, other patients are able to provide conceptual explanation about objects but fail to organize correct actions to and with these objects (De Renzi \& Lucchelli, 1988; Ochipa et al., 1989, 1992). Such dissociations have been taken as evidence that two independent subsystems - one for object semantics and one for action semantics - underlie representations of familiar objects. The results of the present study could thus suggest that action words are processed through separate pathways, one giving semantic information about the words (i.e. their meaning, the entities they relate to, in which context they are encountered etc.), and the other providing pragmatic/functional information about how the actions they refer to can be performed.

In conclusion, the present study reveals that processing of action verbs can be selectively affected in PD patients off dopaminergic treatment, but that this deficit can recover following Levodopa intake. Although we still need to better understand the functional role of motor regions in action word understanding, our findings provide evidence that processing of actionrelated language partly relies on the motor system. 


\section{Acknowledgements}

We thank all patients and control participants for their participation in this study. This work was supported by the CNRS and Université Claude Bernard, Lyon. V.B. was also supported by a fellowship from the MENRT (Ministère de l'Education Nationale, de la Recherche et des Transports). T.A.N. is member of the Marie Curie Research and Training Network: Language and Brain (RTN: LAB) funded by the European Commission (MRTN-CT-2004-512141) as part of its Sixth Framework Program. 


\section{Bibliography}

Alexander, G.E., DeLong, M.R., \& Strick, P.L. (1986). Parallel organization of functionally segregated circuits linking basal ganglia and cortex. Annual Review of Neuroscience, 9, $357-381$.

Angwin, A.J., Chenery, H.J., Copland, D.A., Murdoch, B.E., \& Silburn, P.A. (2003). Summation of semantic priming in Parkinson's disease and healthy individuals. Brain and Language, 87, 96-97.

Angwin, A.J., Chenery, H.J., Copland, D.A., Murdoch, B.E., \& Silburn, P.A. (2004a). The time course of semantic activation in Parkinson's disease. Brain and Language, 91, 145146.

Angwin, A.J., Chenery, H.J., Copland, D.A., Arnott, W.L., Murdoch, B.E., \& Silburn, P.A. (2004b). Dopamine and semantic activation: An investigation of masked direct and indirect priming. Journal of International Neuropsychology Society, 10, 15-25.

Arnott, W.L., Chenery, H.J., Murdoch, B.E., \& Silburn, P.A. (2001). Semantic priming in Parkinson's disease: Evidence for delayed spreading activation. Journal of Clinical and Experimental Neuropsychology, 23, 502-519.

Aziz-Zadeh, L., Maeda, F., Zaidel, E., Mazziotta, J., \& Iacoboni, M. (2002). Lateralization in motor facilitation during action observation: a TMS study. Experimental Brain Research, 144(1), 127-131.

Aziz-Zadeh, L., Iacoboni, M., Zaidel, E., Wilson, S., \& Mazziotta, J. (2004). Left hemisphere motor facilitation in response to manual action sounds. European Journal of Neuroscience, 19(9), 2609-2612. 
Aziz-Zadeh, L., Wilson, S.M., Rizzolatti, G., \& Iacoboni, M. (2006). Congruent embodied representations for visually presented actions and linguistic phrases describing actions. Current Biology, 16, 1818-1823.

Bak, T.H., O’Donovan, D.G., Xuereb, J.H., Boniface, S., \& Hodges, J.R. (2001). Selective impairment of verb processing associated with pathological changes in Brodmann areas 44 and 45 in the motor neurone disease-dementia-aphasia syndrome. Brain, 124, 103-120.

Bak, T.H., \& Hodges, J.R. (2004). The effects of motor neurone disease on language: further evidence. Brain and Language, 89(2), 354-361.

Bak, T.H., Yancopoulo, D., Nestor, P.J., Xuereb, J.H., Spillantini, M.G., Pulvermüller, F., \& Hodges, J.R. (2006). Clinical, imaging and pathological correlates of a hereditary deficit in verb and action processing. Brain, 129(2), 321-332.

Beatty, W.W., \& Monson, N. (1989). Lexical processing in Parkinson's disease and multiple sclerosis. Journal of Geriatry Psychiatry and Neurology, 2, 145-152.

Beck, A.T., Ward, C.H., Mendelson, M., Mock, J., \& Erbaugh, J. (1961). An inventory for measuring depression. Archives of General Psychiatry, 4, 561-571.

Beck, A.T. (1979). Cognitive therapy and emotional disorders. New York, American library.

Bertella, L., Albani, G., Greco, E., Priano, L., Mauro, A., Marchi, S., Bulla, D., \& Semenza, C. (2002). Noun verb dissociation in Parkinson's disease. Brain and Cognition, 48(2-3), 277280.

Binkofski, F., \& Buccino, G. (2006). The role of ventral premotor cortex in action execution and action understanding. Journal of Physiology Paris, 99(4-6), 396-405.

Bloxham, C.A., Dick, D.J., \& Moore, M. (1987). Reaction times and attention in Parkinson's disease. Journal of Neurology Neurosurgery and Psychiatry, 50(9), 1178-1183. 
Boulenger, V., Roy, A.C., Paulignan, Y., Déprez, V., Jeannerod, M., \& Nazir, T,A. (2006). Cross-talk between language processes and overt motor behavior in the first $200 \mathrm{~ms}$ of processing. Journal of Cognitive Neuroscience, 18(10), 1607-1615.

Boulenger, V., Decoppet, N., Roy, A.C., Paulignan, Y., \& Nazir, T.A. (2007). Differential effects of Age-of-Acquisition for concrete nouns and action verbs: Evidence for partly distinct representations? Cognition, 103(1), 131-146.

Buccino, G., Binkofski, G., Fink, G.R., Fadiga, L., Fogassi, L., Gallese, V., Seitz, R.J., Zilles, K., Rizzolatti, G., \& Freund, H.J. (2001). Action observation activates the premotor and parietal areas in a somatotopic manner: an fMRI study. European Journal of Neuroscience, $13,400-404$

Buccino, G., Lui, F., Canessa, N., Patteri, L., Lagravinese, G., Benuzzi, F., Porro, C.A., \& Rizzolatti, G. (2004). Neural circuits involved in the recognition of actions performed by nonconspecifics: an FMRI study. Journal of Cognitive Neuroscience, 16(1), 124-126.

Buccino, G., Riggio, L., Melli, G., Binkofski, F., Gallese, V., \& Rizzolatti G. (2005). Listening to action-related sentences modulates the activity of the motor system: a combined TMS and behavioral study. Cognitive Brain Research, 24(3), 355-363.

Buxbaum, L.J., Schwartz, M.F., \& Carew, T.G. (1997). The role of semantic memory in object use. Cognitive Neuropsychology, 14, 219-254.

Caramazza, A., \& Hillis, A.E. (1991). Lexical organization of nouns and verbs in the brain. Nature, 349, 788-790.

Copland, D.A., Chenery, H.J., \& Murdoch, B.E. (2000). Understanding ambiguous words in biased sentences: Evidence of transient contextual effects in individuals with nonthalamic subcortical lesions and Parkinson's disease. Cortex, 36, 601-622.

Damasio, A.R., \& Tranel, D. (1993). Nouns and verbs are retrieved with differently neural systems. Proceedings of the National Academy of Sciences, 90, 4957-4960. 
Daniele, A., Giustolisi, L., Silveri, M.C., Colosimo, S., \& Gainotti, G. (1994). Evidence for a possible neuroanatomical basis for lexical processing of nouns and verbs. Neuropsychologia, 32(11), 1325-1341.

Dehaene, S., Naccache, L., Cohen, L., Bihan, D.L., Langin, J.F., Poline, J.B., \& Riviere, D. (2001). Cerebral mechanisms of word masking and unconscious repetition priming. Nature Neuroscience, 4(7), 752-758.

DeLong, M.R. (1990). Primate models of movement disorders of basal ganglia origin. Trends in Neurosciences, 13(7), 281-285.

De Renzi, E., \& Lucchelli, F. (1988). Ideational apraxia. Brain, 111, 1173-1185.

Dick, J., Cantello, R., Buruma, O., Gioux, M., Benecke, R., Day, B.L., Rothwell, J.C., Thompson, P.D., \& Marsden, C.D. (1987). The Bereitschaftspotential, L-DOPA and Parkinson's disease. Electroencephalography and Clinical Neurophysiology, 66(3), 263274.

Fadiga, L., Fogassi, L., Pavesi, G., \& Rizzolatti, G. (1995). Motor facilitation during action observation: a magnetic stimulation study. Journal of Neurophysiology, 73, 2608-2611.

Fahn, S., Elton, R.L., and the members of the UPDRS Development Committee. (1987). Unified Parkinson's disease rating scale. In S. Fahn, C.D. Marsden, M. Goldstein \& D.B. Calne, editors. Recent developments in Parkinson's disease. Vol.II. (pp.153-163). Florham Park, NJ: Macmillan.

Ferrand, L., Grainger, J., \& Segui, J. (1994). A study of masked form priming in picture and word naming. Memory and Cognition, 22(4), 431-441.

Forster, K.I., \& Davis, C. (1984). Repetition priming and frequency attenuation in lexical access. Journal of Experimental Psychology: Learning, Memory and Cognition, 10, 680698. 
Gallese, V., Fadiga, L., Fogassi, L., \& Rizzolatti, G. (1996). Action recognition in the premotor cortex. Brain, 119(2), 593-609.

Gallese, V., \& Lakoff, G. (2005). The brain's concepts: The role of the sensory-motor system in conceptual knowledge. Cognitive Neuropsychology, 22, 455-479.

Gibb, W.R., \& Lees, A.J. (1988). The relevance of the Lewy body to the pathogenesis of idiopathic Parkinson's disease. Journal of Neurology Neurosurgery and Psychiatry, 51, $745-752$

Gilhooly, K.J., \& Logie, R.H. (1980). Methods and designs: Age of acquisition, imagery, concreteness, familiarity, and ambiguity measures for 1,944 words. Behavor Research Methods Instruments, 12, 395-427.

Greenwald, A.G., Draine, S.C., \& Abrams, R.L. (1996). Three cognitive markers of unconscious semantic activation. Science, 273(5282), 1699-1702.

Grossman, M., Carvell, S., Gollomp, S., Stern, M.B., Vernon, G., \& Hurtig, H.I. (1991). Sentence comprehension and praxis deficits in Parkinson's disease. Neurology, 41, 16201626.

Grossman, M., Carvell, S., Stern, M.B., Gollomp, S., \& Hurtig, H.I. (1992). Sentence comprehension in Parkinson's disease: The role of attention and memory. Brain and Language, 42, 347-384.

Grossman, M., Stern, M.B., Gollomp, S., Vernon, G., \& Hurtig, H.I. (1994). Verb learning in Parkinson's disease. Neuropsychology, 8, 413-23.

Grossman, M. (1999). Sentence processing in Parkinson's disease. Brain and Cognition, 40, $387-413$

Grossman, M., Zurif, E., Lee, C., Prather, P., Kalmanson, J., Stern, M.B., \& Hurtig, H.I. (2002). Information processing speed and sentence comprehension in Parkinson's disease. Neuropsychology, 16(2), 174-181. 
Grossman, M., Glosser, G., Kalmanson, J., Morris, J., Stern, M.B., \& Hurtig H.I. (2001). Dopamine supports sentence comprehension in Parkinson's Disease. Journal of Neurological Sciences, 184(2), 123-130.

Grossman, M., Carvell, S., \& Peltzer, L. (2005). The sum and substance of it: the appreciation of mass and count quantifiers in Parkinson's disease. Brain and Language, 44(4), 351-384.

Haslinger, B., Erhard, P., Kampfe, N, Boecker, H., Rummeny, E., Schwaiger, M., Conrad, B., \& Ceballos-Baumann, A.O. Event-related functional magnetic resonance imaging in Parkinson's disease before and after levodopa. Brain, 124(3), 558-570.

Hauk, O., Johnsrude, I., \& Pulvermüller, F. (2004). Somatotopic representation of action words in human motor and premotor cortex. Neuron, 41, 301-307.

Hauk, O., Patterson, K., Woollams, A., Watling, L., Pulvermüller, F., \& Rogers, T.T. (2006). When would you prefer a SOSSAGE to a SAUSAGE? At about $100 \mathrm{msec}$. ERP correlates of orthographic typicality and lexicality in written word recognition. Journal of Cognitive Neuroscience, 18(5), 818-832.

Hillis, A.E., Wityk, R.J., Barker, P.B., \& Caramazza, A. (2003). Neural regions essential for writing verbs. Nature Neuroscience, 6, 19-20.

Hodges, J.R., Garrard, P., \& Patterson, K. (1998). Semantic dementia. In A. Kertesz \& D.G. Munoz, editors. Pick's disease and Pick complex (pp.83-104). New York: Wiley-Liss.

Jahanshahi, M., Jenkins, I.H., Brown, R.G., Marsden, C.D., Passingham, R.E., \& Brooks, D.J. (1995). Self-initiated versus externally triggered movements. I. An investigation using measurement of regional cerebral blood flow with PET and movement-related potentials in normal and Parkinson's disease subjects. Brain, 119(3), 1045-1048.

Jeannerod, M. (1994). The representing brain: Neural correlates of motor intention and imagery. Behavorial Brain Sciences, 17(2), 187-524. 
Jeannerod, M., \& Frak, V. (1999). Mental imaging of motor activity in humans. Current Opinion in Neurobiology, 9(6), 735-739.

Jenkins, I.H., Fernandez, W., Playford, E.D., Lees, A.J., Frackowiak, R.S., Passingham, R.E., \& Brooks, D.J. (1992). Impaired activation of the supplementary motor area in Parkinson's disease is reversed when akinesia is treated with apomorphine. Annals of Neurology, 32(6), 749-757.

Kischka, U., Kammer, T., Maier, S., Weisbrod, M., Thimm, M., \& Spitzer, M. (1996). Dopaminergic modulation of semantic network activation. Neuropsychologia, 34, 11071113

Kohler, E., Keysers, C., Umiltà, M.A., Fogassi, L., Gallese, V., \& Rizzolatti, G. (2002). Hearing sounds, understanding actions: action representation in mirror neurons. Science, 297, 846-848.

Lauro-Grotto, R., Piccini, C., \& Shallice, T. (1997). Modality-specific operations in semantic dementia. Cortex, 33, 593-622.

Lieberman, P., Friedman, J., \& Feldman, L.S. (1990). Syntax comprehension in Parkinson's disease. Journal of Nervous Mental Disease, 178, 360-366.

Lieberman, P., Kako, E., Friedman, J., Tajchman, G., Feldman, L.S., \& Jiminez, E.B. (1992). Speech production, syntax comprehension, and cognitive deficits in Parkinson's disease. Brain and Language, 43, 169-189.

Mahon, B.Z., \& Caramazza, A. (2005). The orchestration of the sensory-motor systems: Clues from neuropsychology. Cognitive Neuropsychology, 22(3/4), 480-494.

Martin, A., Wiggs, C.L., Ungerleider, L.G., \& Haxby, J.V. (1996). Neural correlates of category-specific knowledge. Nature, 379, 649-652.

Mason, M.F., Banfield, J.F., \& Macrae, C.N. (2004). Thinking about actions: the neural substrates of person knowledge. Cerebral Cortex, 14, 209-214. 
Natsopoulos, D., Katsarou, Z., Bostantzopoulos, S., Grouios, G., Mentenopoulos, G., \& Logothetis, J. (1991). Strategies in comprehension of relative clauses in Parkinsonian patients. Cortex, 27, 255-268.

New, B., Pallier, C., Ferrand, L., \& Matos, R. (2001). Une base de données lexicales du français contemporain sur internet : LEXIQUE. L'Année Psychologique, 101, 417-462.

Oishi, M., Mochizuki, Y., Du, C., \& Takasu, T. (1995). Contingent negative variation and movement-related cortical potentials in parkinsonism. Electroencephalography and Clinical Neurophysiology, 95(5), 346-349.

Oldfield, R.C. (1971). The assessment and analysis of handedness: the Edinburgh Inventory. Neuropsychologia, 9, 97-113.

Oliveri, M., Finocchiaro, C., Shapiro, K., Gangitano, M., Caramazza, A., \& Pascual-Leone, A. (2004). All talk and no action: a transcranial magnetic stimulation study of motor cortex activation during action word production. Journal of Cognitive Neuroscience, 16(3), 374381.

Ochipa, C., Rothi, L.J., \& Heilman, K.M. (1989). Ideational apraxia: a deficit in tool selection and use. Annals of Neurology, 23, 190-193.

Ochipa, C., Rothi, L.J., \& Heilman, K.M. (1992). Conceptual apraxia in Alzheimer's disease. Brain, 115, 1061-1071.

Peran, P., Rascol, O., Demonet, J.F., Celsis, P., Nespoulous, J.L., Dubois, B., \& Cardebat, D. (2003). Deficit of verb generation in nondemented patients with Parkinson's disease. Movement Disorders, 18(2), 150-156.

Pillon, B., Boller, F., Levy, R., \& Dubois, B. (2001). Cognitive deficits and dementia in Parkinson's disease. In F. Boller \& S. Cappa, editors. Aging and dementia, vol 6, (pp.311371). Elsevier Science BV, Amsterdam. 
Playford, E.D., Jenkins, I.H., Passingham, R.E., Nutt, J., Frackowiak, R.S., \& Brooks, D.J. (1992). Impaired mesial frontal and putamen activation in Parkinson's disease: a positron emission tomography study. Annals of Neurology, 32(2), 151-161.

Preissl, H., Pulvermüller, F., Lutzenberger, W., \& Birbaumer, N. (1995). Evoked potentials distinguish between nouns and verbs. Neuroscience Letters, 197, 81-83.

Pulvermüller, F. (1996). Hebb's concept of cell assemblies and the psychophysiology of word processing. Psychophysiology, 33, 317-333.

Pulvermüller, F. (2001). Brain reflections of words and their meaning. Trends in Cognitive Sciences, 5, 517-525.

Pulvermüller, F. (2005). Brain mechanisms linking language and action. Nature Review Neuroscience, 6, 576-582.

Pulvermüller, F., Lutzenberger, W., \& Preissl, H. (1999). Nouns and verbs in the intact brain: Evidence from event-related potentials and high-frequency cortical responses. Cerebral Cortex, 9, 497-506.

Pulvermüller, F., Shtyrov, Y., \& Ilmoniemi, R. (2005a). Brain signatures of meaning access in action word recognition. Journal of Cognitive Neuroscience, 17(6), 1-9.

Pulvermüller, F., Hauk, O., Nikulin, V.V., \& Ilmoniemi, R.J. (2005b). Functional links between motor and language systems. European Journal of Neuroscience, 21(3), 793-797.

Rascol, O., Sabatini, U., Chollet, F., Celsis, P., Montastruc, J.L., Marc-Vergnes, J.P., \& Rascol, A. (1992). Supplementary and primary sensory motor area activity in Parkinson's disease. Regional cerebral blood flow changes during finger movements and effects of apomorphine. Archives of Neurology, 49(2), 144-148.

Rascol, O., Sabatini, U., Chollet, F., Fabre, N., Senard, J.M., Montastruc, J.L., \& Rascol, A. (1994). Normal activation of the supplementary motor area in patients with Parkinson's 
disease undergoing long-term treatment with levodopa. Journal of Neurology Neurosurgery and Psychiatry, 57(5), 567-571.

Rizzolatti, G., Fadiga, L., Gallese, V., \& Fogassi, L. (1996a). Premotor cortex and the recognition of motor actions. Brain Research Cognitive Brain Research, 3, 131-141.

Rizzolatti, G., Fadiga, L., Matelli, M., Bettinardi, V., Paulesu, E., Perani, D., \& Fazio, F. (1996b). Localization of grasp representations in humans by PET: 1. Observation versus execution. Experimental Brain Research, 111(2), 246-252.

Rizzolatti, G., \& Fadiga, L. (2004). The mirror-neuron system and action recognition. In H.J. Freund, M. Jeannerod \& M. Hallett, editors. Higher-order motor disorders: from Neuroanatomy and Neurobiology to Clinical Neurology. New York: Oxford University Press.

Sauseng, P., Bergmann, J., \& Wimmer, H. (2004). When does the brain register deviances from standard word spellings? An ERP study. Brain Research Cognitive Brain Research, $20(3), 529-532$.

Schmidt, R., Freidl, W., Fazekas, F., Reinhart, B., Grieshofer, P., Koch, M., Eber, B., Schumacher, M., Polimn, K., \& Lechner, H. (1994). The Mattis Dementia Rating Scale: normative data from 1,001 healthy volunteers. Neurology, 44, 964-966.

Sereno, S.C., \& Rayner, K. (2003). Measuring word recognition in reading: eye movements and event-related potentials. Trends in Cognitive Sciences, 7(11), 489-493.

Shibasaki, H., Shima, F., \& Kuroiwa, Y. (1978). Clinical studies of the movement-related cortical potential (MP) and the relationship between the dentatorubrothalamic pathway and readiness potential (RP). Journal of Neurology, 219(1), 15-25.

Shtyrov, Y., Hauk, O., \& Pulvermüller, F. (2004). Distributed neuronal networks for encoding category-specific semantic information: the mismatch negativity to action words. European Journal of Neuroscience, 19(4), 1083-1092. 
Spitzer, M., \& Neumann, M. (1996). Noise in models of neurological and psychiatric disorders. International Journal of Neural Systems, 7, 355-361.

Tettamanti, M., Buccino, G., Saccuman, M.C., Gallese, V., Danna, M., Scifo, P., Fazio, F., Rizzolatti, G., Cappa, S.F., \& Perani, D. (2005). Listening to action-related sentences activates fronto-parietal motor circuits. Journal of Cognitive Neuroscience, 17, 273-281.

Thobois S. (2006). Proposed dose equivalence for rapid switch between dopamine receptor agonists in Parkinson's Disease: a review of literature. Clinical Therapy, 28, 1-12. 
TABLE 1: Characteristics of PD patients. Age, Gender, Disease Duration, Dopa Equivalence and scores obtained for the different tests assessing motor disability (UPDRS Part III, maximal score $=108)$ during the OFF- and ON-phases, cognitive status (DRS, $\max =144$; BDI, max $=63$ ) and laterality (Edinburgh Inventory, $\max =1$ ) are reported for each PD patient. Means (and standard deviations) are noted in bold in the last row of the table. M, male; F, female. Dopa equivalence: $100 \mathrm{mg}$ Dopa $=10 \mathrm{mg}$ bromocriptine $=6 \mathrm{mg}$ ropinirole $=$ $1 \mathrm{mg}$ pergolide $=1 \mathrm{mg}$ pramipexole $=60 \mathrm{mg}$ piribedil (see Thobois, 2006).

\begin{tabular}{|c|c|c|c|c|c|c|c|c|c|}
\hline \multirow[b]{2}{*}{ Patients } & \multirow[b]{2}{*}{ Age (years) } & \multirow[b]{2}{*}{ Gender } & \multirow{2}{*}{$\begin{array}{c}\text { Disease } \\
\text { Duration } \\
\text { (years) }\end{array}$} & \multirow{2}{*}{$\begin{array}{c}\text { Dopa } \\
\text { Equivalence } \\
(\mathbf{m g} / \mathbf{d})\end{array}$} & \multicolumn{2}{|c|}{ UPDRS } & \multirow[b]{2}{*}{ DRS } & \multirow[b]{2}{*}{ BDI } & \multirow{2}{*}{$\begin{array}{l}\text { Edinburgh } \\
\text { Inventory }\end{array}$} \\
\hline & & & & & OFF & ON & & & \\
\hline PD1 & 57 & $\mathrm{~F}$ & 14 & 1000 & 44 & 7 & 131 & 21 & 1 \\
\hline PD2 & 64 & $\bar{F}$ & 16 & 700 & 42 & 27 & 131 & 20 & 1 \\
\hline PD3 & 72 & $\mathrm{~F}$ & 17 & 1300 & 29 & 14,5 & 137 & 28 & 0,9 \\
\hline PD4 & 55 & $\mathrm{M}$ & 7 & 700 & 38 & 15 & 136 & 13 & 0,9 \\
\hline PD5 & 65 & $\mathrm{M}$ & 7 & 1450 & 23,5 & 5,5 & 139 & 6 & 0,75 \\
\hline PD6 & 67 & $\mathrm{M}$ & 1 & 600 & 26 & 25,5 & 127 & 15 & 0,89 \\
\hline PD7 & 62 & $M$ & 7 & 765 & 30,5 & 16 & 135 & 14 & 1 \\
\hline PD8 & 58 & $\mathrm{M}$ & 9 & 850 & 31,5 & 20 & 138 & 23 & 0,9 \\
\hline PD9 & 79 & M & 12 & 450 & 33 & 24 & 129 & 11 & 1 \\
\hline PD10 & 49 & $\mathrm{~F}$ & 10 & 750 & 33,5 & 13 & 132 & 17 & 0,89 \\
\hline $\begin{array}{c}\text { MEAN } \\
\text { (SD) }\end{array}$ & $\begin{array}{l}62.8 \\
(8.7) \\
\end{array}$ & & $\begin{array}{c}10 \\
(4.8)\end{array}$ & $\begin{array}{l}856.5 \\
(311)\end{array}$ & $\begin{array}{l}33.1 \\
(6.6)\end{array}$ & $\begin{array}{l}16.75 \\
(7.4)\end{array}$ & $\begin{array}{c}133.5 \\
(4)\end{array}$ & $\begin{array}{l}16.8 \\
(6.4)\end{array}$ & $\begin{array}{c}.92 \\
(.07)\end{array}$ \\
\hline
\end{tabular}


TABLE 2: Mean values (and standard deviations) of word frequency (FQ), length in letters (LETT), number of syllables (SYLL), bigram (BIGR) and trigram frequency (TRIG), age-ofacquisition (AoA), imageability (IMAG), and analyses of variance (ANOVAs) by items, for nouns, verbs and pseudo-words. (ns), non significant.

\begin{tabular}{|c|c|c|c|c|c|}
\cline { 2 - 6 } \multicolumn{1}{c|}{} & NOUNS & VERBS & ANOVA (by items) & $\begin{array}{c}\text { PSEUDO- } \\
\text { WORDS }\end{array}$ & ANOVA (by items) \\
\hline FQ & $10.53(32)$ & $10.4(30)$ & {$[\mathrm{F}(1,138)=.001 ; \mathrm{p}=\mathrm{ns}]$} & - & - \\
\hline LETT & $6.57(.94)$ & $6.57(.94)$ & $* * * * *$ & $6.57(.94)$ & $* * * *$ \\
\hline SYLL & $2.11(.55)$ & $2.24(.60)$ & {$[\mathrm{F}(1,138)=1.737 ; \mathrm{p}=\mathrm{ns}]$} & $2.21(.52)$ & {$[\mathrm{F}(1,278)=.190 ; \mathrm{p}=\mathrm{ns}]$} \\
\hline BIGR & $4109(2348)$ & $4676(2584)$ & {$[\mathrm{F}(1,138)=1.842 ; \mathrm{p}=\mathrm{ns}]$} & $4379(1960)$ & {$[\mathrm{F}(1,278)=.003 ; \mathrm{p}=\mathrm{ns}]$} \\
\hline TRIG & $505(434)$ & $571(621)$ & {$[\mathrm{F}(1,138)=.532 ; \mathrm{p}=\mathrm{ns}]$} & $472(443)$ & {$[\mathrm{F}(1,278)=1.27 ; \mathrm{p}=\mathrm{ns}]$} \\
\hline AoA & $4.38(1.2)$ & $4.11(1.3)$ & {$[\mathrm{F}(1,138)=1.556 ; \mathrm{p}=\mathrm{ns}]$} & - & - \\
\hline IMAG & $4.48(.95)$ & $4.22(.70)$ & {$[\mathrm{F}(1,138)=3.196 ; \mathrm{p}=\mathrm{ns}]$} & - & - \\
\hline
\end{tabular}


TABLE 3: Performance in the two priming conditions (consonants-prime and identical-prime) for nouns and verbs stimuli. Net priming effects are also given. Means and standard deviations (SD) are reported in italics in the two last rows of the table. Grey fields indicate negative priming effects (i.e. shorter reaction times in the consonants-prime than in the identical-prime condition). (a) For the ten control participants (C1 to $\mathrm{C} 10$ ); (b) For the ten PD patients in the OFF-phase (PD1 to PD10); (c) For the eight PD patients in the ON-phase (PD1 to PD8; PD9 and PD10 could not perform the experiment in ON).

(a)

\begin{tabular}{|l|c|c|c|c|c|c|}
\cline { 2 - 7 } \multicolumn{1}{c|}{} & \multicolumn{3}{c|}{ NOUNS } & \multicolumn{3}{c|}{ VERBS } \\
\hline CONTROL & consonants & identical & net priming & consonants & identical & net priming \\
\hline C1 & 688 & 633 & $\mathbf{5 5}$ & 593 & 536 & $\mathbf{5 7}$ \\
\hline C2 & 781 & 662 & $\mathbf{1 1 9}$ & 686 & 607 & $\mathbf{7 9}$ \\
\hline C3 & 734 & 696 & $\mathbf{3 8}$ & 712 & 672 & $\mathbf{4 0}$ \\
\hline C4 & 749 & 705 & $\mathbf{4 4}$ & 715 & 660 & $\mathbf{5 5}$ \\
\hline C5 & 736 & 712 & $\mathbf{2 4}$ & 726 & 683 & $\mathbf{4 3}$ \\
\hline C6 & 795 & 727 & $\mathbf{6 8}$ & 807 & 784 & $\mathbf{2 3}$ \\
\hline C7 & 826 & 741 & $\mathbf{8 5}$ & 837 & 774 & $\mathbf{6 3}$ \\
\hline C8 & 992 & 887 & $\mathbf{1 0 5}$ & 943 & 880 & $\mathbf{6 3}$ \\
\hline C9 & 1017 & 1045 & $\mathbf{- 2 8}$ & 945 & 937 & $\mathbf{8}$ \\
\hline C10 & 998 & 997 & $\mathbf{1}$ & 1000 & 1031 & $\mathbf{- 3 1}$ \\
\hline Mean & 832 & 781 & $\mathbf{5 1}$ & 796 & 756 & $\mathbf{4 0}$ \\
\hline SD & 124 & 144 & 46 & 133 & 155 & 32 \\
\hline
\end{tabular}

(b)

\begin{tabular}{|l|c|c|c|c|c|c|}
\cline { 2 - 7 } \multicolumn{1}{c|}{} & \multicolumn{3}{c|}{ NOUNS } & \multicolumn{3}{c|}{ VERBS } \\
\hline PD off & consonants & identical & net priming & consonants & identical & net priming \\
\hline PD1 & 971 & 890 & $\mathbf{8 1}$ & 967 & 950 & $\mathbf{1 7}$ \\
\hline PD2 & 1052 & 945 & $\mathbf{1 0 7}$ & 900 & 935 & $\mathbf{- 3 5}$ \\
\hline PD3 & 786 & 735 & $\mathbf{5 1}$ & 797 & 770 & $\mathbf{2 7}$ \\
\hline PD4 & 1034 & 915 & $\mathbf{1 1 9}$ & 872 & 857 & $\mathbf{1 5}$ \\
\hline PD5 & 927 & 861 & $\mathbf{6 6}$ & 955 & 902 & $\mathbf{5 3}$ \\
\hline PD6 & 1080 & 1049 & $\mathbf{3 1}$ & 997 & 983 & $\mathbf{1 4}$ \\
\hline PD7 & 1292 & 1317 & $\mathbf{- 2 5}$ & 1284 & 1263 & $\mathbf{2 1}$ \\
\hline PD8 & 1042 & 899 & $\mathbf{1 4 3}$ & 934 & 942 & $\mathbf{- 8}$ \\
\hline PD9 & 833 & 783 & $\mathbf{5 0}$ & 827 & 792 & $\mathbf{3 5}$ \\
\hline PD10 & 1209 & 1021 & $\mathbf{1 8 8}$ & 1185 & 1261 & $\mathbf{- 7 6}$ \\
\hline Mean & 1023 & 942 & $\mathbf{8 1}$ & 972 & 966 & $\mathbf{6}$ \\
\hline SD & 155 & 163 & 61 & 153 & 171 & 37 \\
\hline
\end{tabular}


(c)

\begin{tabular}{|l|c|c|c|c|c|c|}
\cline { 2 - 7 } \multicolumn{1}{c|}{} & \multicolumn{3}{c|}{ NOUNS } & \multicolumn{3}{c|}{ VERBS } \\
\hline PD on & consonants & identical & net priming & consonants & identical & net priming \\
\hline PD1 & 770 & 679 & $\mathbf{9 1}$ & 825 & 764 & $\mathbf{6 1}$ \\
\hline PD2 & 785 & 804 & $\mathbf{- 1 9}$ & 716 & 728 & $\mathbf{- 1 2}$ \\
\hline PD3 & 822 & 739 & $\mathbf{8 3}$ & 848 & 780 & $\mathbf{6 8}$ \\
\hline PD4 & 826 & 814 & $\mathbf{1 2}$ & 797 & 818 & $\mathbf{- 2 1}$ \\
\hline PD5 & 874 & 912 & $\mathbf{- 3 8}$ & 909 & 845 & $\mathbf{6 4}$ \\
\hline PD6 & 939 & 863 & $\mathbf{7 6}$ & 1046 & 922 & $\mathbf{1 2 4}$ \\
\hline PD7 & 1016 & 986 & $\mathbf{3 0}$ & 1109 & 1072 & $\mathbf{3 7}$ \\
\hline PD8 & 1154 & 1023 & $\mathbf{1 3 1}$ & 1043 & 1015 & $\mathbf{2 8}$ \\
\hline PD9 & $*$ & $*$ & $*$ & $*$ & $*$ & $*$ \\
\hline PD10 & $*$ & $*$ & $*$ & $*$ & $*$ & $*$ \\
\hline Mean & 898 & 853 & $\mathbf{4 6}$ & 912 & 868 & $\mathbf{4 4}$ \\
\hline SD & 132 & 118 & 59 & 140 & 124 & 47 \\
\hline
\end{tabular}


FIGURE 1: Experimental Design. Grey boxes schematically indicate the different stimuli. Numerals plotted under each box denote corresponding display durations in milliseconds. The oblique axis on the right illustrates the temporal sequence of the stimuli and gives the onset of the corresponding item (time 0 corresponds to the onset of the fixation cross). SOA (Stimulus Onset Asynchrony, i.e. time interval between the onset of the prime and the onset of the target) is $150 \mathrm{~ms}$.

FIGURE 2: Mean performance of the eight PD patients during the ON- and OFF-phases together with performance of the 10 healthy controls. Data are plotted for noun- (in white) and verb-stimuli (in black) as a function of priming conditions (consonants-prime and identical-prime). $(*)$ indicates significant net priming effects (i.e. difference between reaction times in the identical-prime and the consonants-prime conditions); (ns), non significant. 
FIGURE 1

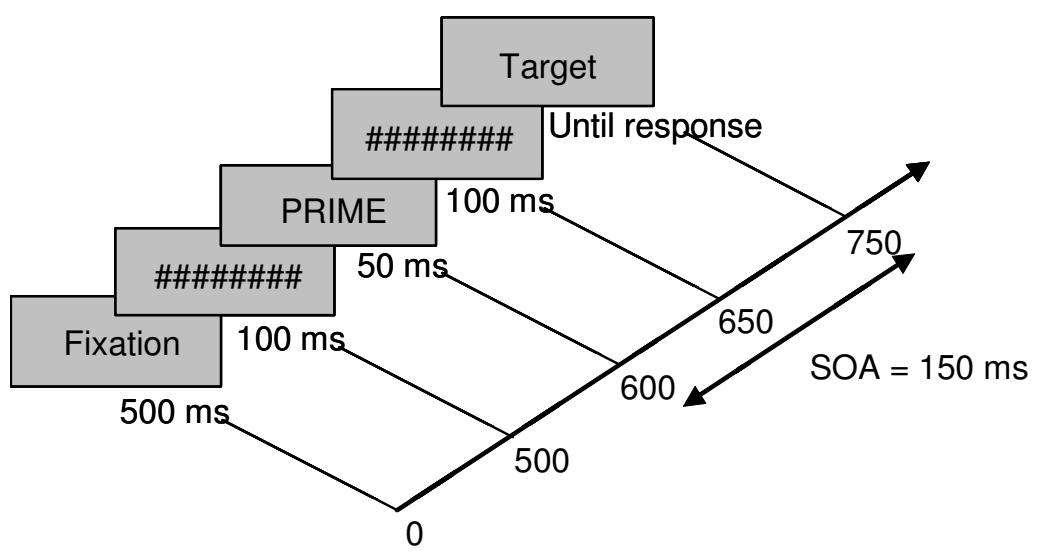

FIGURE 2

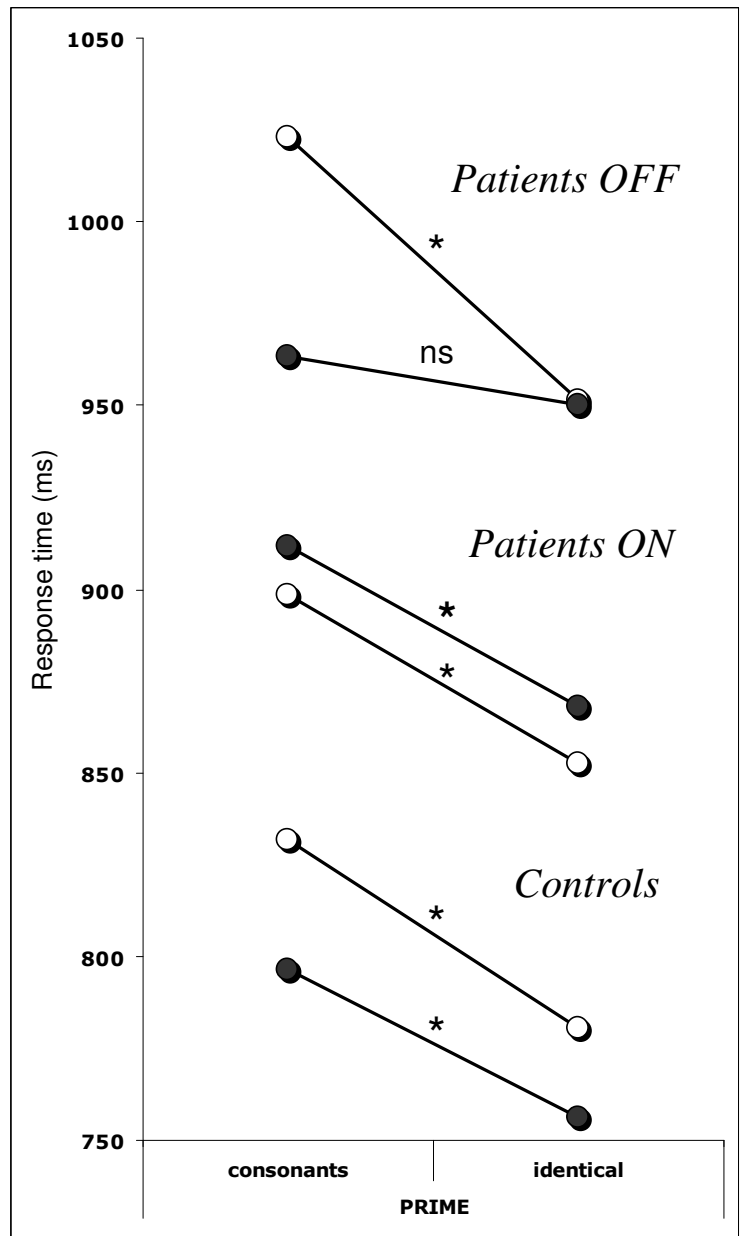

